\title{
[4 + 2] Cycloadditions of Diphenylketene with a Highly Substituted 1,3-Diene
}

\section{Herbert Mayr* and Ulrich W. Heigl}

Institut für Chemie, Medizinische Universität zu Lübeck, Ratzeburger Allee 160, D-2400 Lübeck 1, Federal Republic of Germany

Diphenylketene (2) undergoes [4 + 2] cycloadditions with the s-cis fixed diene (1) to give the dihydropyran (3) and the cyclohexenone (4).

Ketenes undergo $[2+2]$ cycloadditions with alkenes or 1,3-dienes to give cyclobutanones.1,2 Stepwise $[4+2]$ cycloaddition reactions across the $\mathrm{C}=\mathrm{O}$ double bond have been observed when donor (alkoxy and trimethylsiloxy) substituted 1,3-dienes react with alkyl-, aryl-, or halogenoketenes, ${ }^{3}$ and when the electron deficient bis(trifluoromethyl)ketene reacts with buta-1,3-diene. ${ }^{4}$ In some cases, the $\mathrm{C}=\mathrm{C}$ double bond of diphenylketene has been found to act as a

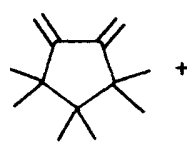

(1)<smiles>O=C=C(c1ccccc1)c1ccccc1</smiles>

(2)

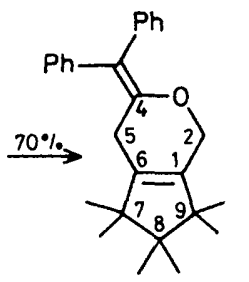

(3)

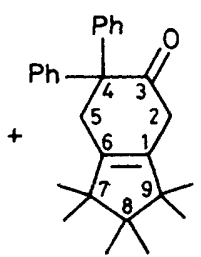

(4) dienophile towards $\alpha, \beta$-unsaturated ketones, imines, and benzoquinone diimines. ${ }^{5}$ We now report the first Diels-Alder reaction of the $\mathrm{C}=\mathrm{C}$ bond of a ketene with an alka-1,3-diene in which the usually occurring $[2+2]$ process is sterically disfavoured. Compound (1), prepared by heating 1,2-bis(bromomethyl)-3,3,4,4,5,5-hexamethylcyclopentane ${ }^{6}$ with magnesium in tetrahydrofuran (THF), has previously been reported to give 1,4-adducts with carbenes. ${ }^{7}$

When compounds (1) and (2) were heated in cyclohexane at $55^{\circ} \mathrm{C}$ for 15 days, a $1: 1$ mixture $(70 \%)$ of (3) and (4) was obtained, which was separated by medium pressure liquid chromatography [silica gel, hexane-ether $(95: 5)] . \dagger$ In the

† Compound (3): m.p. $128.5-129.5^{\circ} \mathrm{C} ;{ }^{1} \mathrm{H}$ n.m.r.: $\delta 0.80(\mathrm{~s}, 6 \mathrm{H})$, $0.83(\mathrm{~s}, 6 \mathrm{H}), 0.95(\mathrm{~s}, 6 \mathrm{H}), 2.68\left(\mathrm{~m}, 2 \mathrm{H}, 5-\mathrm{H}_{2}\right), 4.37\left(\mathrm{~m}, 2 \mathrm{H}, 2-\mathrm{H}_{2}\right)$, 6.9-7.3 (m, $10 \mathrm{H}) ;{ }^{13} \mathrm{C}$ n.m.r. $\left(\mathrm{CDCl}_{3}\right): \delta 24.41(\mathrm{t}, \mathrm{C}-5), 65.48(\mathrm{t}$, C-2). Compound (4): m.p. $97.5-98.5^{\circ} \mathrm{C}$; ${ }^{1} \mathrm{H}$ n.m.r.: $\delta 0.75(\mathrm{~s}, 6 \mathrm{H})$, $0.78(\mathrm{~s}, 6 \mathrm{H}), 1.03(\mathrm{~s}, 6 \mathrm{H}), 2.78(\mathrm{~s}, 2 \mathrm{H}), 3.02(\mathrm{~s}, 2 \mathrm{H}), 7.12-7.33(\mathrm{~m}$, $10 \mathrm{H}) ;{ }^{13} \mathrm{C}$ n.m.r. $\left(\mathrm{CDCl}_{3}\right): \delta 36.25,36.94(2 \mathrm{t}, \mathrm{C}-2,5)$, i.r. $(\mathrm{KBr}): 1705$ $\mathrm{cm}^{-1}(\mathrm{C}=\mathrm{O})$. 


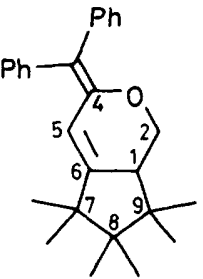

(5)

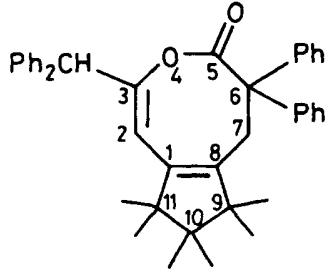

(6) presence of acid, compound (3) readily isomerises to give the conjugated diene (5), and the solvents used for the n.m.r. spectroscopy of (3) have to be neutralised carefully.

In several runs, the reaction of (1) with (2) yielded the $2: 1$ product (6) instead of (3). The structure of (6) was elucidated using the ${ }^{13} \mathrm{C}-{ }^{13} \mathrm{C}$ coupling constants determined by the INADEQUATE pulse sequence. $\neq$ Compound (3) did not react with (2) in the presence of triethylamine or azoisobutyronitrile at $80^{\circ} \mathrm{C}$ but gave (6) when catalytic amounts of $\mathrm{ZnCl}_{2}$ were present. Electrophilic catalysis, therefore, appears to be responsible for the formation of (6).

When the reaction of (1) with (2) was carried out in

$¥$ An analogous structure was postulated for the [2:1] product from bis(trifluoromethyl)ketene and buta-1,3-diene (Yu. A. Cheburkov, N. Mukhamadeliev, and I. L. Knunyautis, Tetrahedron, 1968, 24, 1341 , but discounted later. ${ }^{4}$ benzonitrile instead of cyclohexane, the product ratio (3): (4) increased from $1: 1$ to $3: 1$ while the reaction rate increased by a factor of $c a$. 6. Since diphenylketene (2), like (1), has only a small dipole moment, the small $k(\mathrm{PhCN}) / k\left(\mathrm{C}_{6} \mathrm{H}_{12}\right)$ ratio argues against the formation of a dipolar intermediate in the rate determining step.

We thank R. Koschinsky for carrying out the n.m.r. experiments, and the Deutsche Forschungsgemeinschaft and the Fonds der Chemischen Industrie for financial support.

Received, 6th July 1987; Com. 938

\section{References}

1 R. Huisgen and P. Otto, Chem. Ber., 1969, 102, 3475.

2 R. B. Woodward and R. Hoffmann, Angew. Chem., Int. Ed. Engl., $1969,8,781$

3 J. C. Martin, P. G. Gott, V. W. Goodlett, and R. H. Hasek, J. Org. Chem., 1965, 30, 4175; J. P. Gouesnard, Tetrahedron, 1974, 30, 3113; W. T. Brady and M. O. Agho, J. Heterocycl. Chem., 1983, 20, 501.

4 D. C. England and C. G. Krespan, J. Org. Chem., 1970, 35, 3300.

5 R. Gompper, Angew. Chem., Int. Ed. Engl., 1969, 8, 312; W. Friedrichsen and H.-G. Oeser, Chem. Ber., 1975, 108, 31.

6 H. Mayr, E. Will, U. W. Heigl, and C. Schade, Tetrahedron, 1986, 42, 2519.

7 H. Mayr and U. W. Heigl, Angew. Chem., Int. Ed. Engl., 1985, 24, 579. 